Tétreault, S., et al. (2021). Intercultural Experiences Prior to the Educational Program: Occupational Therapy and Social Work Students

\title{
Intercultural Experiences Prior to the Educational Program: Occupational Therapy and Social Work Students
}

\author{
Sylvie Tétreault* \\ Haute école de travail social et de la santé \\ Carine Bétrisey \\ Haute école de travail social et de la santé \\ Camille Brisset \\ Université de Bordeaux \\ Alida Gulfi \\ Haute école de travail social et de la santé \\ Martine Schaer \\ Haute école de travail social et de la santé \\ Yvan Leanza \\ Université Laval, École de psychologie \\ Nicolas Kühne \\ Haute école de travail social et de la santé \\ *Corresponding Author: sylvie.tetreault@eesp.ch \\ Received : 2019-08-06 \\ Rev. Req. : 2019-09-10 \\ Accepted : 2020-10-08
}

dol $10.46303 /$ jcve.2020.6

How to cite this paper: Tétreault, S., Bétrisey, C., Brisset, C., Gulfi, A., Schaer, M., Leanza, Y. and Kühne, N. (2021). Intercultural Experiences Prior to the Educational Program: Occupational Therapy and Social Work Students. Journal of Culture and Values in Education, 4(1), 15-33, https://doi.org/10.46303/jcve.2020.6

This is an Open Access article distributed under the terms of the Creative Commons Attribution 4.0 International license (https://creativecommons.org/licenses/by/4.0/).

\section{Abstract}

In the health and social professions, including occupational therapy and social work, interactions and exchanges with people are essential. Populations encountered by professionals in these fields are becoming increasingly diverse in terms of age, origin, language, health status, and socio-economic background. Sometimes, professionals can have potential misinterpretations regarding intentions and actions, health beliefs and practices, or verbal and non-verbal communication. To overcome obstacles related to practice in a context of diversity, universities must develop students' intercultural competence. Scientific literature stresses the importance of encountering diversity to improve awareness and sensitivity and to bring attention to biases and prejudices. Considering students' intercultural experiences before their 
Tétreault, S., et al. (2021). Intercultural Experiences Prior to the Educational Program: Occupational Therapy and Social Work Students formation could be a basis to achieve this educational goal. The present study aims to document this topic. Semi-structured interviews with 51 first-year students from two educational institutions in French-speaking Switzerland were conducted to capture the participants' descriptions of these experiences in private or professional contexts. The interviews were transcribed and submitted to a thematic analysis approach. A thematic map was generated and three main themes emerged: (1) perception of diversity; (2) communication challenges; and (3) transformation of attitudes toward the "Other." They are described and discussed in terms of developing intercultural competence. Recommendations regarding intercultural education emerge from these findings.

Keywords: Diversity, Intercultural Competence, Intercultural Experience

\section{Introduction}

In the health and social professions, including occupational therapy and social work, interactions and exchanges with people are essential (Egan, 2017). Populations encountered are becoming increasingly diverse in terms of age, origin, language, health status, and socioeconomic background (Cai, 2016; Donoso Brown, Muñoz, \& Powell, 2011; Hall \& Theriot, 2016; Reyneke, 2017). Therefore, professionals can face difficulties because of potential misinterpretations regarding intentions and actions, health beliefs and practices, or verbal and non-verbal communication (Cai, 2016; Govender, Mpanza, Carey, Jiyane, Andrews, \& Mashele, 2017; Hall \& Theriot, 2016). This situation can alter the trust and relationship between individuals and lead to inappropriate interventions (Govender et al., 2017; Hammell, 2013). In order to deal with these obstacles, guidelines recommend the development of intercultural competence, whether in health or social work (Beagan, 2015; Cai, 2016; Hall \& Theriot, 2016; Hammell, 2013; Henderson, Horne, Hills, \& Kendall, 2018; Kohli, Huber, \& Faul, 2010; Nadan, 2016; Sonn \& Vermeulen, 2018). In other words, professionals should adopt an open and respectful attitude toward people with different cultural backgrounds. Intercultural competence also requires questioning oneself and increasing one's cultural knowledge and coping skills to providing sensitive and appropriate interventions (Beagan, 2015; Cai, 2016; Henderson et al., 2018; Kohli et al., 2010).

According to several authors (Beagan, 2015; Cai, 2016; Donoso Brown et al., 2011; Govender et al., 2017; Hall \& Theriot, 2016; Kohli et al., 2010; Murden, Norman, Ross, Sturdivant, Kedia, \& Shah, 2008), being exposed to diversity is one of the most effective ways to acquire intercultural competence. Diversity means being exposed to cultures and persons with demographics and characteristics different from one's own (Beagan, 2015). Therefore, it is relevant to document students' experience encountering "Others" prior to their educational program because they are new to the health and social fields. "Others" refers to people perceived as possessing a significant difference. The extent to which the experiences of these future professionals can explain their attitudes and behaviors should be documented. The present study aims to explore, through interviews, the significant intercultural encounters of occupational therapy and social work students before their first year of the educational 
Tétreault, S., et al. (2021). Intercultural Experiences Prior to the Educational Program: Occupational Therapy and Social Work Students program. First, diversity and intercultural competence are defined. Then, a narrative review of the scientific literature on intercultural experiences and their impacts is presented. Finally, results and discussion are exposed.

\section{Diversity and Intercultural Competencies}

Many authors (Beagan, 2015; Cai, 2016; Donoso Brown et al., 2011; Hall \& Theriot, 2016; Henderson et al., 2018; Reyneke, 2017) affirm that diversity must be understood in its broadest sense. They believe that this should not only include ethnicity or nationality, but also age, gender, appearance, sexual orientation, religion, language, socio-economic class, and physical and mental condition. Cai (2016) and Kohli and colleagues (2010) assert that these different elements are "cultural markers" that have an effect on people's beliefs, values, norms, traditions, or habits. They also guide their behaviors. Fedor (2014) explains that encounters with the Other, perceived as a carrier of a significant cultural difference, can destabilize professionals and, more so, students during their first year of study.

Adopting culturally competent care and services is strongly recommended for healthcare (Beagan, 2015; Cai, 2016; Henderson et al., 2018) and social work (Hall \& Theriot, 2016; Kohli et al., 2010; Reyneke, 2017). These intercultural skills tend to reduce discrimination and health disparities (Beagan, 2015; Conley et al., 2017; Donoso Brown et al., 2011; Henderson et al., 2018; Kohli et al., 2010) such as access to services, waiting time, and negative remarks. This approach encourages the implementation of a respectful strategy by integrating cultural elements into the interventions (Cai, 2016; Henderson, 2018). Intercultural skills develop in a dynamic process. It is a long-term learning process, advancing in progression and regression steps (Beagan, 2015; Cai, 2016; Govender et al., 2017). According to Cai (2016), the training of culturally competent practice consists of four components. The first component is related to becoming aware of one's own cultural background. This means examining by self-reflection and questioning one's own values, attitudes, beliefs, practices, and patterns of thinking, and also biases, prejudices, and stereotypes vis-à-vis other worldviews and behaviors (Beagan, 2015; Cai, 2016; Cohen-Emerique, 2011; Conley, Deck, Miller, \& Borders, 2017; Hall \& Theriot, 2016; Henderson et al., 2018; Kohli et al., 2010; Nadan, 2016; Reyneke, 2017). A second component involves awareness and sensitivity with regard to the values, beliefs, and attitudes of culturally different clients (Beagan, 2015; Cai, 2016; Cohen-Emerique, 2011; Hall \& Theriot, 2016; Kohli et al., 2010; Murden et al., 2008). It requires openness, respect, empathy and curiosity toward others (Beagan, 2015; Cai, 2016; Kohli et al., 2010; Reyneke, 2017). A third component corresponds to the acquisition of cultural knowledge, namely, what specific groups believe and why, and what their practices are (what is accepted or not), to better understand those elements (Beagan, 2015; Cai, 2016; Kohli et al., 2010; Nadan, 2016; Reyneke, 2017). However, Nadan (2016) warns against the danger of overgeneralization, stereotyping, and the development of "folkloric" or "exotic" views of other cultures. The last component, to develop cultural competence, includes specific skills such as effective communication (verbal and nonverbal) and integration of cultural knowledge into the intervention (e.g., choice of appropriate resources and strategies, culturally relevant occupations and goals) (Beagan, 2015; Cai, 2016; Govender et al., 2017; Hall \& Theriot, 2016; Murden et al., 2008; Nadan, 2016). 
Tétreault, S., et al. (2021). Intercultural Experiences Prior to the Educational Program: Occupational Therapy and Social Work Students In view of the foregoing, university health and social work programs must develop students' cultural awareness and sensitivity. They need to transmit appropriate functional knowledge and skills (Donoso Brown et al., 2011; Hall \& Theriot, 2016; Henderson et al., 2018; Kohli et al., 2010; Murden et al., 2008; Nadan, 2016). Although no clear guidelines could be found in the literature consulted, a large number of learning techniques are proposed: adventure-based activities (Conley et al., 2017; Reyneke, 2017), storytelling (Carter-Black, 2007), multiculturalinfused courses and multicultural supervision (Hall \& Theriot, 2016), interracial communication courses (Govender et al., 2017), case studies (Donoso Brown et al., 2011; Murden et al., 2008), reflective journals (Donoso Brown et al., 2011), group discussions (Donoso Brown et al., 2011; Hall \& Theriot, 2016; Nadan, 2016), experiential education (Conley et al., 2017; Donoso Brown et al., 2011; Kohli et al., 2010), immersion, study abroad (Donoso Brown et al., 2011), and fieldwork (Conley et al., 2017; Donoso Brown et al., 2011; Hall \& Theriot, 2016). Kohli and colleagues (2010) propose three recommendations about multicultural training practices for students: (1) focus on experiential learning; (2) transmit educational and knowledge components; (3) encourage exposure and interactions with populations of different cultural backgrounds. Many studies also stress the importance of encountering diversity to improve awareness and sensitivity and to diminish biases and prejudices (Beagan, 2015; Cai, 2016; Donoso Brown et al., 2011; Govender et al., 2017; Hall \& Theriot, 2016; Henderson et al., 2018; Kohli et al., 2010; Murden et al., 2008). The next section will focus on these experiences and their effects.

\section{Encountering the Other and its Effects}

For many authors, the influence of meeting people with different cultural backgrounds is crucial to intercultural competence development (Beagan, 2015; Cai, 2016; Donoso Brown et al., 2011; Govender et al., 2017; Hall \& Theriot, 2016; Henderson et al., 2018; Kohli et al., 2010; Murden et al., 2008). Nevertheless, experiences with diversity are not sufficient during classroom training and internships (Donoso Brown et al., 2011; Govender et al., 2017; Murden et al., 2008). Therefore, taking into account the students' intercultural experiences before the first year of their educational program could provide an opportunity to better understand their situation and to propose some recommendations to improve their cultural competence. It is also an opportunity to explore with future professionals their beliefs and attitudes, whether positive or negative, toward people with diverse cultural backgrounds.

Although conducted with teachers, the study of Jokikokko (2009) gives an example of development of cultural competence and relationship to the Other. The author assumes that intercultural competence is "a lifelong identity process." She carried out an analysis of 10 biographical interviews with Finnish teachers about the role of "Significant Others." Results show how Others can transform attitudes toward diversity. Attitudes and behaviors of family members with different cultural backgrounds (e.g., tolerance, open-mindedness, or the opposite, as stereotypes and labelling) may influence the relationship. Sometimes, teachers showed a change of attitude following a self-critique of their a priori opinions (Jokikokko, 2009). The author, thus, highlighted the development of teachers' self-awareness and cultural consciousness through intercultural encounters. 
Tétreault, S., et al. (2021). Intercultural Experiences Prior to the Educational Program: Occupational Therapy and Social Work Students No study has been found in the scientific literature about the development of intercultural competence for occupational therapy and social work students in university settings. Therefore, it seems relevant to explore similar areas of research, such as medicine. For example, Dogra, Reitmanova, and Carter-Pokras (2009) pointed out that medical students do not believe that they need to learn about diversity; these participants think that living in a multicultural world or belonging to a minority group is enough to be culturally competent. Interested in students from six liberal art colleges and universities, King, Perez, and Shim (2013) analyzed their intercultural experiences in order to know how they developed their intercultural competence. From 207 stories, the authors listed the contexts of encountering Others, how participants felt before and after these experiences, and how they interacted with these Others. King and colleagues (2013) found that students were delighted to have had direct access to other worldviews, realities, and practices. According to the participants, these experiences allowed them to improve their understanding of the reality of people with other cultural backgrounds (King et al., 2013). The analyzed stories also highlighted how a safe environment allows people to engage in more questioning from their own points of view (King et al., 2013). The last result concerns how much students got involved in the interactions (from listening and observing, to empathizing with others), being more or less active, and having more or less cognitive and emotional implications. King and colleagues (2013) noticed how intercultural experiences help participants change their ethnocentric vision and suspend their negative judgments. Another study (Root \& Ngampornchai, 2012) examined 18 papers from university students in the United States, in which students reflected about their experience with education abroad (e.g., study programs or international internships). Three types of acquired skills are cited: cognitive, behavioral, and affective. Concerning cognitive skills, participants acquired general information about the economy, politics, and history of the region in which they stayed (Root \& Ngampornchai, 2012). According to these authors, a contrasting method was often used by students to describe the other culture, underlining characteristics that differed from their own culture. Root and Ngampornchai (2012) observed that acquiring this culture-specific knowledge about the other group did not lead them to be more aware of their own cultural background. As for behavioral skills, the authors distinguished two main elements, namely, language and communication skills and living skills. Being in an environment where the language is different than their own led students to develop their knowledge of a foreign language. They resorted to using many gestures and nonverbal communication skills (Root \& Ngampornchai, 2012). Concerning living skills, students emphasized learning about food, public transportation, and community habits. The authors hypothesized that these three domains are those with the largest difference from their own lifestyle. The third point is related to affective skills. This included awareness, respect, and understanding about the attitudes and values of members of other cultural groups. Students evoked open-mindedness, reflexivity and critical capacities, dealing with multiple perspectives, and overcoming stereotypes. However, Root and Ngampornchai (2012) expressed some doubts about the depth of changes in students' attitudes and values, in the sense that their actions do not reflect them. In the same way, Odağ, Wallin, and Kedzior (2016) examined how undergraduates define intercultural competence. Participants emphasized the understanding and awareness of cultural backgrounds other than their own. As in the study of Root and Ngampornchai (2012), students do not seem to consider the influence of their own cultural background. 
Tétreault, S., et al. (2021). Intercultural Experiences Prior to the Educational Program: Occupational Therapy and Social Work Students Given the lack of data regarding occupational therapy and social work students, the present study aims to document their intercultural experiences prior to entering their first year of study. The fact that students are new in these professional areas requires that they be trained to practice in a context of diversity. By documenting effects of these experiences on the students' intercultural competence, recommendations concerning intercultural education will be made.

\section{Method}

\section{Research Design}

This study is part of a three-year mixed-methods project that aims to explore how occupational and social work students develop skills to interact with people from different generations, social and health status, and cultural backgrounds (Authors, 2016-2019). An exploratory study design was chosen (Creswell, 2014; Imbert 2010; Plano Clark, Anderson, Wertz, Zhou, Schumacher, \& Miaskowski, 2015) with three phases of data collection, one per year. The first and third phases consisted of individual semi-structured interviews and online questionnaires. The second phase comprised only an individual semi-structured interview. The present article corresponds to the first qualitative data collection phase.

\section{Participants}

All first-year, full-time students in the occupational therapy and social work programs from two universities of applied sciences in French-speaking Switzerland were invited to participate, voluntarily, in the interviews for the first data collection $(n=644)$. These first-year students were registered in either occupational therapy $(n=105)$ or social work $(n=539)$ programs.

\section{Data Collection Tools}

An interview guide, created following Miles, Huberman, and Saldaña's (2014) recommendations, is presented as follows:

"Meaningful intercultural experiences are situations that 'mark' us, in that they leave a trace beyond mere memory. They guide choices or behaviors later in life. Have you ever had significant intercultural experiences (professional or private)? If so, can you describe an experience that was particularly important for you? Can you tell me the effects of this experience on you (changes of opinion, values)?"

This interview guide was a sufficiently open, broad, and flexible instrument that highlights the specificity, perceptions, and reality of the participants. It allows one to know their lived experience. Open-ended questions were designed to capture the participants' description of "significant intercultural experiences" related to private or professional contexts and gained prior to starting their educational program. These experiences were defined for students as milestone events when meeting with someone with another cultural background (e.g., different behaviors, opinions, worldviews, or values) than their own. They were asked to explain how these experiences (positive or negative) happened, and the extent to which the experience 
Tétreault, S., et al. (2021). Intercultural Experiences Prior to the Educational Program: Occupational Therapy and Social Work Students influenced them in regard to their attitude, way of thinking, or way of considering others. Before the interview, students completed a socio-demographic questionnaire.

Several measures were implemented to increase trustworthiness (Careau \& Vallée, 2014; Carter, Bryant-Lukosius, DiCenso, Blythe, \& Neville, 2014; Shenton, 2004). First, credibility was established through the triangulation of sources and analysts. Participants came from two different programs (occupational therapy and social work) at two different schools. Regular discussions occurred between team members at each step of the data analysis process. Second, dependability and confirmability were checked by asking additional team members to review all analyses and findings. Also, critical decisions and significant events were documented in an audit trail. The same person, who was not associated with either university, conducted all interviews and kept a logbook.

\section{Data Collection}

All potential participants $(n=644)$ were invited by email to participate in an individual semistructured interview. In accordance with the ethical standards of research in Switzerland, approval was obtained from the program directors before contacting the students. Prior to the enrolment, written consent was obtained from all students.

The same person did all the interviews, in one location, using the communication format (face to face, telephone, or Skype) chosen by each participant. Interviews lasted about 30 minutes, according to the amount of information that the person was willing to share (Creswell, 2014). They were audio-recorded with the participant's permission and transcribed verbatim. Anonymity of individuals was assured by using an alphanumeric code instead of names.

\section{Data Analysis}

After a double verification of the accuracy of the audio files with the verbatim transcripts, data were submitted to a thematic analysis approach in order to identify, analyze, and report patterns or themes within data (Braun \& Clarke, 2006; Creswell, 2014; Miles et al., 2014). This method was chosen given the absence of other studies in this area. Using NVivo ${ }^{\circledR}$ software (Version 11), data were labeled and connected. After familiarization with the verbatim transcripts, open coding was used to identify recurring ideas across interviews and to extract the major themes. These patterns are retained for their importance in relation to the research question (Braun \& Clarke, 2006). In an inductive way, initial codes were generated and themes were brought out (Braun \& Clarke, 2006; Creswell, 2014; Maxwell, 2013). Following an iterative process, the thematic map was refined, producing clear definitions and descriptions for each element. All the analyses were carried out on the basis of the verbatim transcriptions in French. Only those quotations presented in this paper were translated by the authors into English.

\section{Findings}

Following the description of the participants and their background, a portrait of the significant intercultural experiences chosen by the students will be presented. Then, the three main 
Tétreault, S., et al. (2021). Intercultural Experiences Prior to the Educational Program: Occupational Therapy and Social Work Students themes resulting from the analysis will be discussed: (1) perception of diversity; (2) communication challenges; (3) transformation of attitudes toward the Other. As no difference appeared between occupational therapy and social work students in the analyses, no distinction is made in the results presentation.

\section{Participant Characteristics}

The convenience sample consisted of the 51 students who agreed to participate, including 22 (43\%) in occupational therapy and 29 (57\%) in social work. Forty-seven women (92\%) and four men (8\%) participated. The respondents' mean age was 23.5 years (SD $=4.2$; range: $19-42$ years). Forty-six participants (90\%) identified a Swiss nationality and five (10\%) represented other nationalities (African or European). Moreover, 17 (33\%) reported a second nationality (i.e., French, Italian, Portuguese). Only two students (4\%) spoke no language other than French. Most students ( $n=30,59 \%)$ spoke one or two languages other than French, while others $(n=19$, $37 \%)$ indicated more than three (mainly English, German, Italian, or Spanish).

Prior to entering an occupational therapy or social work program, 21 participants (41\%) reported having one or more professional qualifications in a variety of other areas (e.g., business, education, nursing, sciences, arts). Among them, three individuals did not work after this initial training, and 12 (57\%) had one to two years' experience. The six others had four to 24 years of work experience.

In regard to their intercultural experience, 35 participants (69\%) had had a journey abroad, selfdescribed as "meaningful." Some had work experience in a foreign country ( $n=12,24 \%)$ or with immigrants $(n=7,14 \%)$. In addition, 14 participants $(28 \%)$ had already had a mixed-couple experience, and 32 respondents (63\%) had close friends from various cultural groups.

\section{Significant Intercultural Experiences}

Students were asked about their significant intercultural experiences before entering their first year of study. They talked about situations where they identified the Other (individual or group) as a bearer of a perceived difference. Some respondents shared intercultural experiences in which they felt themselves to be carriers of differences, or in which others viewed them as the individual who was considered different. Several sources of difference were underlined: origin, nationality, language, religion, age, gender, socio-economic status, and health status. In addition, participants put forward particular beliefs, values, attitudes, or behaviors to people with diverse cultural backgrounds. These could be family, friends, schoolmates, coworkers, recipients of health or social services, or members of cultural groups with no particular connection to the participants. The experiences evoked by students took place in a variety of contexts such as family or couple, school, language courses (mainly abroad), internship or work experiences, humanitarian activities, or simply hobbies or holidays.

Theme 1: Perception of Diversity 
Tétreault, S., et al. (2021). Intercultural Experiences Prior to the Educational Program: Occupational Therapy and Social Work Students The first theme that emerged from the data was the perception of diversity. The way participants perceived diversity varied between two opposing poles, namely, normalization and using contrasting comparisons. Sometimes, embedded within both is a critical awareness of students' own cultural background.

\section{Normalizing Diversity}

Normalizing diversity corresponds to the tendency of participants to consider diversity as selfevident. In fact, as most students reported growing up in diversified neighborhoods or cities, they tended to include intercultural experiences as regular. As such, they struggled to find unique encounters with people from diverse cultural backgrounds. For example, one student (male, 21) described his environment as largely frequented by people of various nationalities. He considers this as "ordinary" and believes that he can easily "deal with many different cultures." In fact, several participants suggested that when the community settings are perceived as predominantly diversified, they do not mobilize the discursive register of "otherness" to categorize a person or a group. In these cases, diversity is not understood in a broad sense, because characteristics of diversity other than nationality or origin were not taken into account by the students.

In a similar way, one student questioned the fact of pointing out singularities in Others for the mere reason that they appear as outliers:

"It's like, well, I have a friend, and typically, he is Black. And suddenly, I found it very sad to point out, like: 'Hey, you're the only Black guy in the class!' Why, well, on what grounds does it make him special?" (female, 22)

What is at play here is not that her classmate is Black, per se, but that he is identified as different because of his skin color alone. According to this person, this was not a relevant difference marker that justifies mention.

\section{Using Contrasting Comparisons}

With an opposite point of view, the second pole placed the emphasis on the differences of the Other rather than the similarities. Students mobilized a variety of markers to represent the diversity they perceived. For example, one informant referred to nationality, as well as the values and practices he attributed to them, to describe his perception of Asian classmates during a language-learning stay in England:

"During this linguistic stay, I was very much with Japanese or Korean people... The thing that remains with me the most was with the friends, well, precisely Japanese, where in their culture, it is rude to look someone in the eyes." (male, 26)

This quote illustrates the ethnocentric vision of this student toward other frames of reference. According to him, Japanese culture considers something that is polite in his own cultural background as rude. In his narrative, the Japanese students' way of being polite constitutes a 
Tétreault, S., et al. (2021). Intercultural Experiences Prior to the Educational Program: Occupational Therapy and Social Work Students deviation from the norm. This student does not adopt a critical perception of his own frame of reference.

In fact, people with diverse cultural backgrounds are often depicted in oppositional terms: "they live in another world" and "it is totally different from here" were recurrent expressions from participants about experiences gained while traveling abroad. This contrast between Us and Them also appears in experiences that occurred in Switzerland. A woman remembered her interactions with a young man from Eastern Europe who had recently moved to Switzerland and was looking for a job:

"For him, he absolutely had to have a job, at such and such age, in order to be able to head a family, because it was obligatory to have a family, to be the one who manages the house, and that the woman must stay at home to take care of everything else. It was vain to try to explain to him that it was fifty-fifty. The woman can work as much as the man. But it was unthinkable, in fact, according to his way of thinking." (female, 22)

She contrasted her cultural background, in which she presupposes that women can work as well as men, with this man's perspective where it is not the case. Her interpretation does not question her own frame of reference, nor aims to accept other values. In other words, she remains centered on her own interpretation of the situation. It does not point to an increased intercultural sensitivity.

The narratives revealed that the cultural markers of perceived difference are typically interpreted in general and oppositional terms. Participants listed, among other things, the "culture of appearance" in South Korea, the "stress-free work culture" in South-East Asia, and the "omnipresence of music" in South America. These examples suggest that the respondents built up generalizing - and often "folklorizing" - representations about local populations. These representations reflect the oppositional divide between Us and Them that contributes to the "exoticization" of Others. In that regard, one informant explained the living conditions of the person who hosted her during a humanitarian stay in South America:

"She lives in a place, it's not even listed, actually. There is not even a street. And then, she built her house. She has three children and she had a husband who was very, very disabled, who is dead now. And she welcomed me home. I had a bed to sleep in and she never asked me anything. That was so amazing, the hospitality I had. ... it was really the sharing between humans that counted and it was beautiful." (female, 27)

This student highlighted a representation of poverty according to which local people escape from the profiteering mind characterizing Western societies and are genuinely generous. Although the respondents were in direct contact with locals, their experiences abroad did not always foster further thinking about their observations and perceptions of their interlocutors' cultural characteristics. Their depictions are marked by generalizing and sometimes folklorizing representations that extended to the whole cultural group and remained unquestioned.

Acquiring a Critical Awareness of One's Own Cultural Background 
Awareness and a critical vision of one's own cultural background seem difficult to reach for many participants. Nevertheless, a few students reflected on their experiences by questioning their own norms and attitudes. During her visit to a Latin American country, a young woman recalls that after being at first quite surprised when local people approached and talked to her, it then set her thinking:

"I said to myself: 'Well, for them, it seems normal to them to talk like that.' We can say to ourselves: 'Why are we so scared here to talk to strangers?'” (female, 42)

As she reflected about people's behaviors "here" (in Switzerland) and "there" (in Latin America), this informant evokes the possibility of changing her own practices and possibly even broader social conventions. She describes a more complex view of social realities and includes her familiar environment into her reflections.

\section{Theme 2: Communication Challenges}

Communication challenges form the second main theme that emerges from the analyses. In the many intercultural experiences collected, communication is depicted as the major source of difficulties. But communication can also be the way to resolve misunderstandings or better understand the differences.

\section{Dealing with Communication Barriers}

Sometimes, barriers are identified as the interlocutors' lack of proficiency in the local language for diverse reasons. For example, a participant evokes communication hurdles during an internship with elderly migrants with brain damage. She explains that these people were no longer able to speak French, which complicated interactions:

"It was old people who were, well, who had brain damage. And suddenly, they couldn't speak French anymore, they spoke in their native language." (female, 28)

Another student experienced communication difficulties in his interactions with nursing-home residents whose native language was not French. Encountering similar difficulties, she describes how she handled this situation:

"Speaking more slowly, trying to be ... to use simple words, simple sentences and not extensible, designating things, talking a little with my hands ... and trying another language if the person knew another language." (female, 19)

Several participants claimed that they tried to improve communication by avoiding complicated terms and long sentences. If necessary, they used non-verbal communication or a common foreign language. 
Tétreault, S., et al. (2021). Intercultural Experiences Prior to the Educational Program: Occupational Therapy and Social Work Students Mirroring these barriers, other respondents mentioned their own linguistic limitations while traveling abroad. This example indicates how lack of proficiency in a foreign language might influence perception:

"I could not communicate with others. It was pretty awful, actually. It was the first time I was told: 'Participant name] is a shy girl.' Because, finally, I'm rather extroverted, actually." (female, 22)

Although many respondents pointed out language as an obstacle when they traveled abroad, they did not mention that such experiences allowed them to gain a deeper understanding of the potential linguistic difficulties of their interlocutors in other contexts. One student is an exception, as he explained how he was sensitized:

"On the other hand, I think that what it brought me that was very positive is that I feel that it made me much more sensitive to the difficulties of a person who could not speak the language well." (male, 33)

\section{Overcoming Misunderstandings with Communication}

In addition to the barriers related to the mastery of the language, other communicative issues were evoked by the participants. For example, some students talked about situations in which they at first felt surprised by or wrongly interpreted a norm of behavior they were unfamiliar with. Getting to understand the new norm or environment allowed them to clear up misunderstandings. Having to deal with a different environment while abroad, in particular when it involved a new language, was often emphasized as challenging, at least at the beginning, and required time for adjustment. Being able to communicate with people from another cultural background can help to better understand this context and the behaviors to adopt. For example, remembering his visit to a friend who had moved back to South America, a participant explained how he felt:

"I arrived in a world where I didn't know the rules, the codes. In addition, I haven't necessarily heard very good things about the country [in a security context], so I wasn't very reassured either." (male, 33)

Then he tells how this friend helped him to find his bearings by explaining the rules and the history of the place. This example shows that he had to gain familiarity with local norms. He needed to learn about the situation from a "local" friend in order to feel at ease in an environment that was new to him. Interpersonal communication with this person was a central aspect of the adaptation process. The importance of interpersonal communication was also highlighted by this student, who at first misinterpreted her interlocutor's communication norms:

"In her way of speaking, I felt assaulted every time. ... For example, when she asked for something, there was no 'thank you' or 'please'. And then, one day, I decided to talk to her about 
Tétreault, S., et al. (2021). Intercultural Experiences Prior to the Educational Program: Occupational Therapy and Social Work Students it. ... She could also explain to me that in her language, in Finland, well, 'please' ..., is not a mark of politeness, but of supplication. That's it." (female, 21)

Communicating with the person about what she identified as a problem in their interactions was key for that student to clear up a misunderstanding that made the relationship between the two uncomfortable. In the above examples, engaging in straightforward communication with their interlocutors helped students adapt to new situations or to correct misunderstandings.

\section{Theme 3: Transformation of Attitudes Toward the Other}

The third theme concerns the effects of encountering people from different cultural backgrounds on participants' attitudes. Sometimes, these experiences can change their perceptions. As for the vision of diversity, the participants are between two opposite poles.

Perceiving the Other in a Less Positive Way

Few students reported that direct contacts with people about whom they had prejudices and stereotyped representations did not change their initial opinion or amplify their negative perceptions. For example, one participant explained how a person with mental disorders threatened to kill people during her internship. She admits her fears:

"But it's true that, after that, I told myself that I didn't see myself working very well in an environment like this. Because I found that the people, they were really unstable.... so it put me in a very uncomfortable position. And then, I do not really want to relive it right now." (female, 24)

Sometimes, meeting with the Other can also break the idealized perception participants had. A woman illustrates her own experience after a humanitarian stay in Africa:

"They sent us messages, and they were waiting for us to help them financially. And that's true that it hurts a bit because in itself ... it's true that we have money. But at the same time, they do not necessarily realize our reality either." (female, 21)

In this case, she changed her attitude toward the people she met, but rather in a negative or destabilizing way.

Breaking Prejudices or Stereotypes vis-à-vis the Other

For many participants, directly engaging with people perceived as different allows them to overcome their fears and prejudices. They question stereotyped and generalizing representations of people with other cultural backgrounds. Experiences taking place in various contexts illustrate this outcome. For example, a young woman explained that, when she was a child, her primary school included child refugees: 
Tétreault, S., et al. (2021). Intercultural Experiences Prior to the Educational Program: Occupational Therapy and Social Work Students

"Many of them had their face a little eaten by insects over there. Well, they were very poor. So when they were here, they really had the joy of living, a way of seeing things that was very different from ours. And then, it was something that had struck me a lot when I was young." (female, 22)

She confessed that at first she was afraid of these children. But she ended up enjoying them very much and learned a lot from them. Interacting with these children allowed her to overcome her initial fears and to establish a positive representation of them. Also at school, another woman experienced a situation in which a classmate was discriminated against by the other students because she wore a veil. She says about it:

"Everyone was laughing at her just because she was wearing the veil. And nobody ever went to ask her if it was really her choice. ... then she finally stopped and left the class. Then I thought it was a shame because in the end, it's not because we have a veil that we are different." (female, 20)

Although social prejudices from peers were difficult to question openly, interacting with the stigmatized person allowed her to reflect about and distance herself from her own reaction and her fellow students' biases.

In a professional context, another woman recalls that before starting her internship, she was worried about working with disabled people:

"And actually, once there, it was very easy and very natural to interact with these people, even with people who had difficulty communicating. I could find ways to understand and communicate with them. It reassured me a lot about that and removed the stigma I had, visions I had of the disabled." (female, 21)

It seems that encountering these people allowed the young woman to dispel her concerns and leave prejudices aside. Other examples reveal stereotypical representations based on people's origins. As she babysat children in a family from the Middle East, a student observed that her preconceptions about the culture of this country were not corroborated by her experience. She realized that "it was quite similar to any other family [she] worked for" (female, 21). On the same subject, a female student interacted with a person from Eastern Europe. She doubts the validity of her stereotypes:

"We have a lot of stereotypes about [country's name], about the [people from this country] and how they are. And it was funny, actually, to meet one who destroyed all the stereotypes we had. And this is sometimes when you realize that in fact, we put images, ideas on people, on cultures that, in fact, are not true at all or that may be true only for a minority." (female, 28)

Another example concerns a description of the religious behaviors of an internship supervisor:

"When she told me she was praying all the time, that she was doing 'religious rituals' all the time, I was surprised." (female, 30) 
As she considered her supervisor "very open-minded," she says she had to reassess her idea that "those who pray were not open." These excerpts indicate that by directly interacting with people from other cultural backgrounds, students could confront their preconceptions and fears with their lived experiences. As a result, they put aside their prejudices and change their attitudes.

\section{Discussion and Implications}

Through interviews with 51 participants, the content of their significant intercultural experiences before starting their educational program has been documented, as well as the effects. The students' stories focus on various characteristics considered as markers of difference in various contexts. According to the results, the participants' perception of diversity varies between the normalization and the contrasted vision, highlighting the differences above all. As Dogra and colleagues (2009) found, living in a highly multicultural context would tend to let students think that they don't need special training to intervene in a context of diversity. Moreover, several participants even deny difference markers in order to treat everyone the same way. However, this is not the goal of the intercultural approach in that these differences need to be recognized to provide effective services (Beagan, 2015; Cai, 2016; Hall \& Theriot, 2016; Kohli et al., 2010; Murden et al., 2008).

On the contrary, when students point out the differences in a very contrasting way, this phenomenon is the same as that evoked by Root and Ngampornchai (2012), who indicated that people notice more the characteristics that differ most from their own cultural background. This is also apparent in the present study. Furthermore, participants do not always leave their ethnocentric vision of values, norms, and predetermined normal behaviors. This emerges from their interview when they do not reflect on their own frames of reference in relation to those of the Other, contrary to what King and colleagues (2013) observed. In addition, several students develop what Nadan (2016) calls a "folkloric" or "exotic" vision of other cultural groups. Thus, these groups are perceived as homogeneous. Whether diversity is recognized as normality or exacerbating differences, it seems that students find it difficult to become aware of their own frames of reference. Few of them have been critical of their personal cultural background, although they have discovered other representations of the world. In this sense, intercultural intervention training is necessary to develop these elements of intercultural competence (Beagan, 2015; Cai, 2016; Henderson et al., 2018; Kohli et al., 2010; Reyneke, 2017).

The second main theme that emerges concerns communication challenges. Many of the intercultural experiences cited by the participants were about the difficulties encountered when they or the Other did not master the local language. Various strategies were adopted to overcome this communication barrier, as recommended in the context of intercultural intervention (Cai, 2016; Govender et al., 2017; Henderson et al., 2018). This finding is similar to those of Root and Ngampornchai (2012) about acquired skills, such as using foreign languages or nonverbal communication. Misinterpretations can also be solved through communication with the Other in order to understand their frames of reference. In such cases, as Jokikokko 
Tétreault, S., et al. (2021). Intercultural Experiences Prior to the Educational Program: Occupational Therapy and Social Work Students (2009) shows, exchanging with people from other cultural backgrounds improves selfawareness of norms, values, and a priori attitudes that can lead to misunderstandings.

More broadly, participants identified changes in their attitudes toward people with diverse cultural backgrounds as a result of their significant intercultural experiences. Only rarely was there evidence that the encounter with the Other caused a crystallization of the prejudices or destruction of the idealized image of the latter. Nevertheless, Beagan (2015) notices that this could happen. Similar to stories collected by King and colleagues (2013), students were more delighted or intrigued by other frames of reference. They gained new knowledge about other worldviews, attitudes, and behaviors as a result of the described experiences, just as Root and Ngampornchai (2012) explain about their participants.

In the present study, many people said that they had overcome their initial fears and prejudices toward the Other to establish a positive representation. Comparable observations were made by Jokikokko (2009), King and colleagues (2013), and Root and Ngampornchai (2012) with other populations (teachers, liberal art colleges, and university students). These findings about occupational therapy and social work students seem to confirm that exposure and direct interactions with populations of different cultural backgrounds often increase awareness and sensitivity to the Other while decreasing a priori opinions and discrimination, as claimed by many authors (Beagan, 2015; Cai, 2016; Donoso Brown et al., 2011; Govender et al., 2017; Hall \& Theriot, 2016; Henderson et al., 2018; Kohli et al., 2010; Murden et al., 2008).

Some limitations must be mentioned regarding these results. First of all, as this is a convenience sample, students most interested in the topic of intervention in a context of diversity may have decided to participate in the present study. Furthermore, these are experiences of students from the French-speaking part of Switzerland, which could limit the transferability of the conclusions. However, studies conducted on similar data, but with other populations in other countries, have led to very similar results (Jokikokko, 2009; King et al., 2013; Root \& Ngampornchai, 2012). Even if further validations with other samples of occupational therapy and social work students should be made, recommendations can already be proposed to educational institutions. First, professors should explore with students their previous intercultural experiences. In this way, this information provides concrete examples based on which they could bring students to a critical reflection. According to Cai (2016), they need to become aware of their own frames of reference (i.e., values, attitudes, beliefs, practices, patterns of thinking), biases, prejudices, and stereotypes vis-à-vis other perceptions and behaviors. Basing this awareness on events already experienced would be a first step, so that they could be better prepared to deal with intercultural contacts during their internship. Future health and social work professionals must be aware of the influence of these elements on their practice and learn how to adapt their interventions (Murden et al., 2008; Nadan, 2016). It is therefore essential to approach this aspect with them. However, as noted by King and colleagues (2013), a sense of safety is crucial when it comes to exploring intercultural differences. During the significant experiences reported by the participants in the present study, a safe environment was not often accessible. This could explain why students show difficulties in challenging their prejudices and stereotypes in relation to other worldviews. University 
Tétreault, S., et al. (2021). Intercultural Experiences Prior to the Educational Program: Occupational Therapy and Social Work Students program planners should be careful to provide these learning conditions in order to promote the development of intercultural competences among their students.

\section{Conclusion}

Occupational therapy and social work students do not go into their educational program without knowledge, a priori attitudes, or prejudices concerning interactions with people from other cultural backgrounds. This observation applies to all health and social professions. As direct encounter of the Other is probably the best way to develop a critical view of these prior attitudes, student experiences should be used by teachers to develop their cultural sensitivity. Knowledge and strategies could then be acquired for an efficient practice in a context of diversity.

\section{References}

Beagan, B. L. (2015). Approaches to culture and diversity: A critical synthesis of occupational therapy literature. Canadian Journal of Occupational Therapy, 82, 272-282. doi: $10.1177 / 0008417414567530$

Braun, V., \& Clarke, V. (2006). Using thematic analysis in psychology. Qualitative Research in Psychology, 3, 77-101. doi: 10.1191/1478088706qp063oa

Cai, D.-Y. (2016). A concept analysis of cultural competence. International Journal of Nursing Sciences, 3, 268-273. doi: 10.1016/j.ijnss.2016.08.002

Careau, E., \& Vallée, C. (2014). Qualitative research and scientificity. In S. Tétreault \& P. Guillez (Eds.), Practical guide to rehabilitation research (pp. 489-508). Louvain-la-Neuve, Belgium: De Boeck Supérieur.

Carter, N., Bryant-Lukosius, D., DiCenso, A., Blythe, J., \& Neville, A. J. (2014). The use of triangulation in qualitative research. Oncology Nursing Forum, 41, 545-547. doi:10.1188/14.ONF.545-547

Carter-Black, J. (2007). Teaching cultural competence: An innovative strategy grounded in the universality of storytelling as depicted in African and African American storytelling traditions. Journal of Social Work Education, 43, 31-50. Retrieved July 15, 2019, from http://www.jstor.org/stable/23044222

Conley, C. L., Deck, S. M., Miller, J. J., \& Borders, K. (2017). Improving the cultural competency of social work students with a social privilege activity. Journal of Teaching in Social Work, 37, 234-248. doi: 10.1080/08841233.2017.1313804

Creswell, J. W. (2014). Research design: Qualitative, quantitative and mixed methods approaches (4th ed.). Thousand Oaks, CA: Sage Publications. 
Donoso Brown, E. V., Muñoz, J. P., \& Powell, J. M. (2011). Multicultural training in the United States: A survey of occupational therapy programs. Occupational Therapy in Health Care, 25, 178-193. doi: 10.3109/07380577.2011.560240

Dogra, N., Reitmanova, S., \& Carter-Pokras, O. (2009). Teaching cultural diversity: Current status in U.K., U.S., and Canadian medical schools. Journal of General Internal Medicine, 25, 164-168. doi: 10.1007/s11606-009-1202-7

Egan, G. (2017). The skilled helper. A client-centered approach (2nd ed.). Hampshire, UK: Cengage.

Fedor, C.-G. (2014). Stereotypes and prejudice in the perception of the "Other." ProcediaSocial and Behavioral Sciences, 149, 321-326. doi: 10.1016/j.sbspro.2014.08.257

Godkin, M. A., \& Savageau, J. A. (2001). The effect of a global multiculturalism track on cultural competence of preclinical medical students. Family Medicine and Community Health Publications and Presentations, 33, 178-186. Retrieved July 15, 2019, from http://escholarship.umassmed.edu/fmch_articles/1

Govender, P., Mpanza, D. M., Carey, T., Jiyane, K., Andrews, B., \& Mashele, S. (2017). Exploring cultural competence amongst OT students. Occupational Therapy International, 4, 2179781, 18. doi: 10.1155/2017/2179781

Hall, J. C., \& Theriot, M. T. (2016). Developing multicultural awareness, knowledge, and skills: Diversity training makes a difference? Multicultural Perspectives, 18, 35-41. doi: 10.1080/15210960.2016.1125742

Hammell, K. R. (2013). Occupation, well-being, and culture: Theory and cultural humility. Canadian Journal of Occupational Therapy, 80, 224-234. doi: 10.1177/0008417413500465

Henderson, S., Horne, M., Hills, R., \& Kendall, E. (2018). Cultural competence in healthcare in the community: A concept analysis. Health and Social Care in the Community, 26, 590-603. doi: 10.1111/hsc.12556

Imbert, G. (2010). L'entretien semi-directif: À la frontière de la santé publique et de I'anthropologie. Recherche en Soins Infirmiers, 102, 23-34. doi: 10.3917/rsi.102.0023

Jokikokko, K. (2009). The role of significant others in the intercultural learning of teachers. Journal of Research in International Education, 8, 142-163. doi: 10.1177/1475240909105202

King, P. M., Perez, R. J., \& Shim, W.-J. (2013). How college students experience intercultural learning: Key features and approaches. Journal of Diversity in Higher Education, 6, 69-83. doi: $10.1037 / \mathrm{a} 0033243$ 
Kohli, H. K., Huber, R., \& Faul, A. C. (2010). Historical and theoretical development of culturally competent social work practice. Journal of Teaching in Social Work, 30, 252-271. doi: 10.1080/08841233.2010.499091

Maxwell, J. A. (2013). Qualitative research design. An interactive approach (3rd ed.). Thousand Oaks, CA: Sage Publications.

Miles, M. B., Huberman, A. M., \& Saldaña, J. (2014). Qualitative data analysis (3rd ed.). Thousand Oaks, CA: Sage Publications.

Murden, R., Norman, A., Ross, J., Sturdivant, E., Kedia, M., \& Shah, S. (2008). Occupational therapy students' perceptions of their cultural awareness and competency. Occupational Therapy International, 15, 191-203. doi: 10.1002/oti.253

Nadan, Y. (2016). Teaching Note - Revisiting stereotypes: Enhancing cultural awareness through a web-based tool. Journal of Social Work Education, 52, 50-56. doi: 10.1080/10437797.2016.1113054

Odağ, Ö., Wallin, H. R., \& Kedzior, K. K. (2016). Definition of intercultural competence according to undergraduate students at an international university in Germany. Journal of Studies in International Education, 20(2), 118-139. doi: 10.1177/1028315315587105

Plano Clark, V. L., Anderson, N., Wertz, J. A., Zhou, Y., Schumacher, K., \& Miaskowski, C. (2015). Conceptualizing longitudinal mixed methods designs: A methodological review of health sciences research. Journal of Mixed Methods Research, 9, 297-319. doi: $10.1177 / 1558689814543563$

Reyneke, R. P. (2017). Apples and pears: Engaging social work students in social dialogue. Research on Social Work Practice, 27, 239-247. doi: 10.1177/1049731516669823

Root, E., \& Ngampornchai, A. (2012). "I came back as a new human being": Student descriptions of intercultural competence acquired through education abroad experiences. Journal of Studies in International Education, 17, 513-532. doi: 10.1177/1028315312468008

Shenton, A. K. (2004). Strategies for ensuring trustworthiness in qualitative research projects. Education for Information, 22, 63-75. doi: 10.3233/EFI-2004-22201

Sonn, I., \& Vermeulen, N. (2018). Occupational therapy students' experiences and perceptions of culture during fieldwork education. South African Journal of Occupational Therapy, 48, 3439. doi: 10.17159/2310-3833/2017/vol48n1a7 